\title{
Magnetic Beads Based Immunoaffinity Capillary Electrophoresis of Total Serum IgE with Laser-Induced Fluorescence Detection
}

\author{
Hong-Xu Chen, ${ }^{t, \neq}$ Jean-Marc Busnel, ${ }^{\ddagger}$ Gabriel Peltre, ${ }^{\S}$ Xin-Xiang Zhang,*,† and \\ Hubert H. Girault*** \\ Laboratoire d'Electrochimie Physique et Analytique, Station 6, Ecole Polytechnique Fédérale de Lausanne, \\ CH-1015 Lausanne, Switzerland, Beijing National Laboratory for Molecular Sciences, College of Chemistry, Peking \\ University, Beijing 100871, China, and Laboratoire Environnement et Chimie Analytique, UMR CNRS 7121, \\ ESPCl, Paris, France
}

A magnetic beads based immunoaffinity capillary electrophoresis method for total Immunoglobulin E quantification in serum has been developed. The method combines speed, automation ability, and minimal sample consumption. Only $1 \mu \mathrm{L}$ of serum is required while the whole immunoaffinity capillary electrophoresis method is performed in less than $50 \mathrm{~min}$. The concomitant use of online immunocapture, transient isotachophoresis, and laserinduced fluorescence detection provides a sensitivity in the low picomolar range and a highly linear fluorescence response over 4 orders of magnitude (IgE concentration ranging from 2.4 to $2400 \mathrm{ng} / \mathrm{mL}$ ). After validation with a reference material, the method has been successfully applied to the quantification of total IgEs in patient sera. The results compared well with classical ImmunoCap data.

Immunoglobulin $\mathrm{E}$ ( $\mathrm{IgE}$ ) is a glycoprotein with an average molecular mass of $188000 \mathrm{Da}$, the shortest half-life and the lowest concentration in serum of all the immunoglobulins (IgG, IgA, IgM, $\operatorname{IgD}, \operatorname{IgE}) .{ }^{1}$ For several decades, much attention has been paid to IgE because it plays a very important role in the development of allergy and parasitic diseases. Allergy is an abnormal immunological response due to a sensitization to some components from the environment or food for example. It today represents a major health problem, affecting $10-20 \%$ of the general population worldwide, especially in industrialized countries. ${ }^{2}$ Briefly, the mechanism of IgE-mediated allergic reaction involves antigen presentation, IgE production, mast cell activation, mediator release, and symptom exhibition. ${ }^{3}$ Typical IgE concentration in a new born child is extremely low $(<1.3 \mathrm{kIU} / \mathrm{L}$ where $1 \mathrm{IU}=2.4$ $n g)$. It then increases steadily during childhood, reaching its

* To whom correspondence should be addressed. E-mail: zxx@pku.edu.cn (X.X.Z.), hubert.girault@epfl.ch. (H.H.G.). Tel: +86-10-62754174(X.X.Z.), +4121-6933145(H.H.G.). Fax: +86-10-62751708 (X.X.Z.), +41-21-6933667 (H.H.G.).

${ }^{\dagger}$ Peking University.

* Ecole Polytechnique Fédérale de Lausanne.

$\S$ UMR CNRS 7121, ESPCI.

(1) Harlow, E.; Lane, D. Using antibodies: a laboratory manual; Cold Spring Harbor Laboratory Press: New York; 1999.

(2) Su, X.; Zhang, J. Sens. Actuators, B 2004, 100, 309-314.

(3) Wen, H.-W.; Borejsza-Wysocki, W.; DeCory, T. R.; Durst, R. A. Compr. Rev. Food Sci. Food Saf. 2007, 6, 47-58. highest level between the age of 15 and 35 , and thereafter it remains constant until an age of 60 , when a slow decrease begins. ${ }^{4}$ The average total IgE concentration in a healthy adult is about $90 \mathrm{kIU} / \mathrm{L} .{ }^{5}$ Higher levels usually reflect the presence of allergy.

For many years, in vitro tests for allergy diagnosis have been carried out by different radioallergosorbent tests (RAST), ${ }^{6,7}$ but it has been gradually replaced by a sort of enzyme-linked immunosorbent assay (ELISA). Those are now commercially available and widely known as the Pharmacia Cap or ImmunoCap systems. For the quantification of total serum IgE, a traditional sandwich immunoassay scheme is integrated using two complementary antibodies specific to different epitopes of the $\operatorname{IgE}$ molecule. When classical ELISA methodologies usually require several dozens of microliters of serum and around $24 \mathrm{~h}$ to be performed, total serum IgE quantitation by the ImmunoCap system is carried in about 2 or $3 \mathrm{~h}$ with $50 \mu \mathrm{L}$ of serum. Although ELISA based methodologies provide a suitable sensitivity with a minimal detectable concentration of $\operatorname{IgE}$ of $12 \mathrm{ng} / \mathrm{mL},{ }^{8}$ they involve time-consuming washing and incubating procedures. Consequently, the development of other immunoassay approaches, designed to be rapid, sensitive, and cost-effective, has been pursued over the last years. For example, a technique that uses surface plasmon resonance spectroscopy (SPR) and quartz crystal microbalance (QCM) has been reported, with a linear range of IgE from 5 to $300 \mathrm{IU} / \mathrm{mL}^{2}$ Electrochemical immunosensors using screen-printed carbon electrode technology and amperometric detection were also disclosed with either anti-IgE antibodies or anti-IgE aptamers as receptor molecules. ${ }^{4,9}$ In the former case, a limit of detection (LOD) of $0.09 \mathrm{ng} / \mathrm{mL}$ has been reported. Other label-free biosensors based on aptamer recognition and electrochemical impedance spectroscopy ${ }^{10}$ or carbon

(4) Papamichael, K. I.; Kreuzer, M. P.; Guilbault, G. G. Sens. Actuators, B 2007, 121, 178-186.

(5) Peuravuori, H.; Korpela, T. Clin. Chem. 1993, 39, 846-851.

(6) Kuby, J. Immunology, 3rd ed.; Freeman: New York; 1997; Chapter 5.

(7) Hamilton, R. G.; Adkinson, N. F., Jr. L. Allergy Clin. Immunol. 2004, 114, 213-225.

(8) Immunoglobulin E enzyme immunoassay test kit, catalogue number BC-1035, BioCheck, Inc., CA.

(9) Kreuzer, M. P.; O'Sullivan, C. K.; Pravda, M.; Guilbault, G. G. Anal. Chim. Acta 2001, 442, 45-53.

(10) Xu, D.; Xu, D.; Yu, X.; Liu, Z.; He, W.; Ma, Z. Anal. Chem. 2005, 77, 51075113.

Analytical Chemistry, Vol. 80, No. 24, December 15, 2008

9583 
nanotube field-effect transistors have also been described ${ }^{11}$ with an LOD of 100 or $250 \mathrm{pM}$, respectively. Another report relating to the use of an aptamer based affinity capillary electrophoresis (ACE) provided an LOD of $46 \mathrm{pM}$ for IgE with laser-induced fluorescence (LIF) detector. ${ }^{12}$

Immunoaffinity capillary electrophoresis (IA-CE) is a hybrid technique that combines immunocapture and $\mathrm{CE}$ separation. ${ }^{13-15}$ In online IA-CE, a microextractor or concentrator is introduced near the inlet of the separation capillary, which contains an immunosorbent that specifically retains the target antigen. A large volume of sample can then be injected, and the target analytes specifically captured. Washing and clean up procedures are subsequently integrated online to remove excess sample and nonspecifically bound interferents. The bound analytes are then eluted by means of an appropriate buffer and separated by one or more modes of $\mathrm{CE}$ and finally detected by usual detection techniques. Compared to ELISA techniques, IA-CE has significant advantages. Mainly, it is a miniaturized technique that combines speed, automation, and low sample consumption. Moreover, the analyte concentrator at the forepart of the capillary enables to immunocapture the considered analyte from a percolated sample. Depending on the concentration of the target analytes in the sample, percolation volumes (typically from several tenths of nanoliters to several microliters) can be varied to obtain suitable sensitivity. Additionally, the separation step, subsequent to the immunocapture one, decreases the probability of false positive results as an additional parameter, electrophoretic mobility, could be used for increasing the identification confidence. Furthermore, IA-CE can be coupled to MS, direct identification of the captured antigen through MS analysis could thus be very straightforward. ${ }^{16}$ Several applications of IA-CE have so far been described for peptides and/ or proteins. The main difference between each approach lies in the way to develop the immunosorbent within the capillary. Covalent or non-covalent binding of antibodies directly on the surface of the capillary, ${ }^{17-22}$ functional particles or beads, ${ }^{23-28}$ and monolithic materials ${ }^{29-31}$ are mostly used. So far, to the best of our knowledge, IA-CE has only been applied once to $\operatorname{IgE}$

(11) Machashi, K.; Katsura, T.; Kerman, K.; Takamura, Y.; Matsumoto, K.; Tamiya, E. Anal. Chem. 2007, 79, 782-787.

(12) German, I.; Buchanan, D. D.; Kennedy, R. T. Anal. Chem. 1998, 70, 45404545 .

(13) Guzman, N. A.; Phillips, T. M. Anal. Chem. 2005, 77, 60A-67A.

(14) Amundsen, L. K.; Sirén, H. Electrophoresis 2007, 28, 99-113.

(15) Guzman, N. A.; Stubbs, R. J. Electrophoresis 2001, 22, 3602-3628.

(16) Shaw, C. J.; Guzman, N. A. In Handbook of Pharmaceutical Analysis; Ohannesian, L., Streeter, A. J., Eds.; Marcel Dekker: New York; 2002; pp $313-386$.

(17) Phillips, T. M.; Chmielinska, J. J. Biomed. Chromatogr. 1994, 8, 242-246.

(18) Ensing, K.; Paulus, A. I. Pharm. Biomed. Anal. 1996, 14, 305-315.

(19) Phillips, T. M.; Kennedy, L. M.; De Fabo, E. C. I. Chromatogr. B 1997 , 697, 101-109.

(20) Phillips, T. M. Anal. Chim. Acta 1998, 372, 209-218.

(21) Little, M. K.; Crawley, C. D. Anal. Chim. Acta 2002, 464, 25-35.

(22) Phillips, T. M.; Smith, P. Biomed. Chromatogr. 2003, 17, 182-187.

(23) Cole, L. J.; Kennedy, R. T. Electrophoresis 1995, 16, 549-556.

(24) Guzman, N. A. J. Chromatogr. B 2000, 749, 197-213.

(25) Dalluge, J. J.; Sander, L. C. Anal. Chem. 1998, 70, 5339-5343.

(26) Thomas, D. H.; Rakestraw, D. J.; Schoeniger, J. S.; Lopez-Avila, V.; Van Emon, J. Electrophoresis 1999, 20, 57-66.

(27) Guzman, N. A. Electrophoresis 2003, 24, 3718-3727.

(28) Chen, H. X.; Busnel, J. M.; Gassner, A. L.; Peltre, G.; Zhang, X. X.; Girault, H. H. Electrophoresis 2008, 29, 3414-3421.

(29) Bedair, M.; El Rassi, Z. J. Chromatogr. A 2004, 1044, 177-186.

(30) Faure, K.; Delaunay, N.; Alloncle, G.; Cotte, S.; Rocca, J.-L. L. Chromatogr. A 2007, 1149, 145-150. preconcentration. ${ }^{32}$ Two immunosorbent designs were reported in this study. One of the used designs was a $5 \mathrm{~mm}$ solid-phase cartridge fabricated by assembling a bundle of multiple microcapillaries in which a monoclonal antibody directed against IgE was covalently bound to the surface of every microcapillary, the whole assembly being further connected to a separation capillary through sleeves connectors. The second design described in this study consisted of an analyte concentrator-reaction chamber that was fabricated from a solid rod of glass.

In this work, we present a new approach for determining total serum IgE concentration using IA-CE coupled with LIF detection. The immunosorbent was prepared by covalent binding of antihuman $\mathrm{IgE}$ antibodies $(\mathrm{Ab}(\mathrm{H}))$ to tosyl-activated magnetic beads (MBs), which are further trapped in the capillary via the magnetic field generated by two magnets positioned in an attraction configuration outside the capillary. After having injected the sample and bound IgE molecules on the MBs, a second fluorescently labeled antihuman $\mathrm{IgE}$ antibody $\left(\mathrm{Ab}(\mathrm{D})^{*}\right)$ was used to complete the sandwich format. The two employed antihuman $\operatorname{IgE}$ monoclonal antibodies are known to react on different epitopes of human $\operatorname{IgE}{ }^{33}$ Once the different immunocapture steps have been completed, the immune complexes are dissociated by an acidic buffer, stacked by transient isotachophoresis (t-ITP), and further separated by CZE. The labeled antibody is finally detected by LIF and total $\mathrm{IgE}$ quantification can be achieved. The advantages of the developed approach are its speed, automation, sensitivity, and very small sample consumption. Additionally, as the MBs can be easily trapped and then removed from the capillary, they can be quickly and easily replaced at the beginning of each analysis to avoid potential cross-contamination among samples. Also, depending on the requirements, the amount of MBs can be varied in a given range to adapt the sensitivity. The immunosorbent preparation is thus much easier than with other reported approaches and offers an enhanced versatility.

\section{MATERIALS AND METHODS}

Chemicals. Tosyl-activated superparamagnetic beads of uniform size (mean diameter $1.08 \mu \mathrm{m}$ ) were obtained from Dynabeads (Invitrogen, Oslo, Norway). The reference human $\mathrm{IgE}$ antibody was purchased from National Institute for Biological Standards and Control (NIBSC, U.K.). The mouse antihuman IgE antibody $(\mathrm{H})$ and the mouse antihuman $\operatorname{IgE}$ antibody (D) were purchased from AbD Serotec (Oxford, U.K.). Alexa Fluor 488 monoclonal antibody labeling kit was from Invitrogen (Eugene, Oregon, U.S.A.). Allergic patient sera were obtained from the Laboratoire Environnement et Chimie Analytique (LECA) at Ecole Supérieure de Physique et Chimie Industrielles (ESPCI, Paris, France). Bovine serum albumin (98\%) and polyoxyethylenesorbitan monolaurate (Tween-20) were purchased from SigmaAldrich (Buchs, Switzerland). Hydroxypropylcellulose (HPC) was purchased from Acros (Basel, Switzerland). Acetic acid (99.5\%) was purchased from Fluka (Buchs, Switzerland) and ammonium acetate (98\%) from Merck (Darmstadt, Germany). All the buffers

(31) Armenta, J. M.; Gu, B.; Humble, P. H.; Thulin, C. D.; Lee, M. L. I. Chromatogr. A 2005, 1097, 171-178.

(32) Guzman, N. A. I. Liq. Chromatogr. 1995, 18, 3751-3768.

(33) Mouse anti-Human IgE 5D5 and 5H2, Datasheet 0100-0414\&0100-0413, AbD Serotec, Oxford, U.K. 


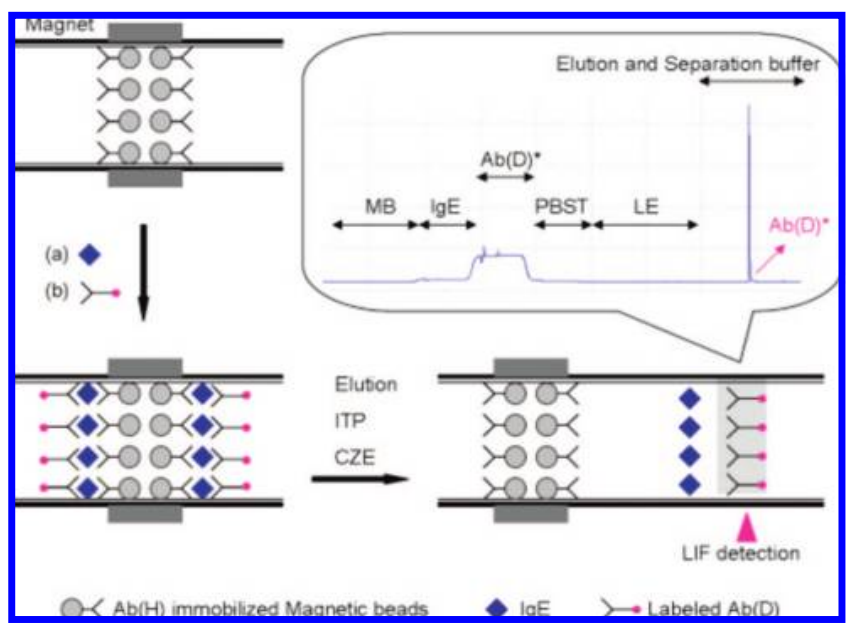

Figure 1. Schematic procedure and typical electropherogram of online sandwich immunoassay of IgE coupled with CE/LIF detection.

and sample solutions were prepared with water produced by an alpha Q Millipore System (Zug, Switzerland).

Buffers used in IA-CE were as follows: binding and washing buffer (phosphate buffer saline with $0.05 \%$ Tween-20 (PBST)); leading electrolyte (LE) (100 mM ammonium acetate, $\mathrm{pH} 7.4$ ); elution and separation buffer (10\% (v/v) acetic acid).

The suspension of $\mathrm{Ab}(\mathrm{H})$ coated MBs $(2 \mathrm{mg} / \mathrm{mL}$ in PBST) was prepared daily by dilution from the stock solution and sonication to reduce aggregation. Reference $\mathrm{IgE}$ stock solution $\left(10000 \mathrm{IU} / \mathrm{mL}\right.$ in water), $\mathrm{Ab}(\mathrm{D})^{*}(0.46 \mathrm{mg} / \mathrm{mL})$ and patient sera were only diluted with binding buffer before use. After collection, the two serum samples of NAC 3 and CER 5 have been aliquoted and stored at $-20^{\circ} \mathrm{C}$ until use. Classical measurements of total $\mathrm{IgE}$ levels were done by means of ImmunoCap by using commercially available tests and reagents, according the instructions of the manufacturer (Phadia AB, Uppsala, Sweden).

Apparatus. All the experiments were carried out on a PACE MDQ system (Beckman-Coulter, Nyon, Switzerland) equipped with an LIF detector (excitation at $488 \mathrm{~nm}$ ), an autosampler, and a power supply able to deliver up to $30 \mathrm{kV}$. Fused-silica capillaries (30/20 $\mathrm{cm}$ total/effective length with $50 / 375 \mu \mathrm{m} \mathrm{id/od)} \mathrm{were}$ obtained from BGB Analytik AG (Böckten, Switzerland) and coated with HPC following the procedure described by Shen et al. ${ }^{34}$ to suppress the electro-osmotic flow and limit as much as possible sample adsorption on the capillary walls. The magnetic field was applied by two round magnets $(\mathrm{Nd}-\mathrm{Fe}-\mathrm{B}, 5 \mathrm{~mm}$ diameter, $2 \mathrm{~mm}$ thickness, SuperMagnete, Zurich, Switzerland), which were placed directly around the capillary in an attraction configuration at a distance of $11 \mathrm{~cm}$ from the inlet. To arrange the magnets around the capillary, the cooling system of the apparatus was disabled and the coolant tube removed. For all immunocapture and washing steps, the flow was driven by the pressure module of the $\mathrm{CE}$ instrument.

Coupling $\mathbf{A b}(\mathbf{H})$ to Magnetic Beads. $\mathrm{Ab}(\mathrm{H})$ was covalently coupled to tosyl-activated MBs, according to the procedure supplied by the manufacturer. A volume of $50 \mu \mathrm{L}$ of tosyl-activated MBs $(100 \mathrm{mg} / \mathrm{mL})$ was washed twice with $100 \mu \mathrm{L}$ of coating buffer (100 mM sodium borate, $\mathrm{pH}$ 9.5). The MBs were then resus-

(34) Shen, Y.; Smith, R. D. L. Microcolumn Sep. 2000, 12, 135-141.

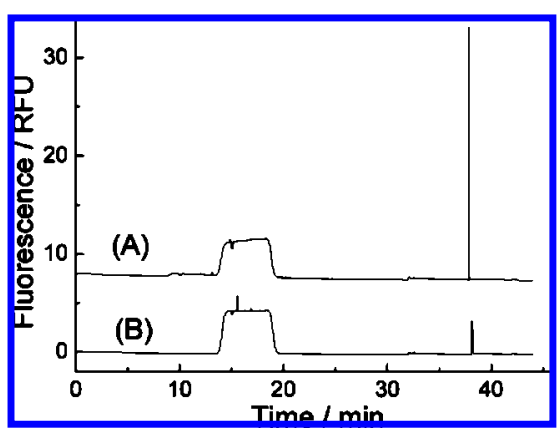

Figure 2. Electropherograms for IgE sample and control. Conditions: HPC coated capillary, total/effective length $30 / 20 \mathrm{~cm} \times 50 \mu \mathrm{m}$ id, LIF detection (488/520 nm excitation/emission). MBs: $A b(H)$ coated, $1.08 \mu \mathrm{m}, 2 \mathrm{mg} / \mathrm{mL}$ in PBST. IgE: $2400 \mathrm{ng} / \mathrm{mL}$ in PBST. Ab(D)*: 575 $\mathrm{ng} / \mathrm{mL}$ in PBST. IA-CE procedure: Injection (34.5 mbar): (A) MBs for $5 \mathrm{~min}$, IgE for $5 \mathrm{~min}, \mathrm{Ab}(\mathrm{D})^{\star}$ for $5 \mathrm{~min}$; (B) MBs for $5 \mathrm{~min}$, PBST for $5 \mathrm{~min}, \mathrm{Ab}(\mathrm{D})^{*}$ for $5 \mathrm{~min}$. Washing (34.5 mbar): PBST for $5 \mathrm{~min}$, ammonium acetate $(100 \mathrm{mM})$ for $10 \mathrm{~min}$. Reverse injection (34.5 mbar): separation buffer for 2 min. Elution and separation: applied voltage, $15 \mathrm{kV}$. MBs removal (1379 mbar): separation buffer for 2 $\min$.

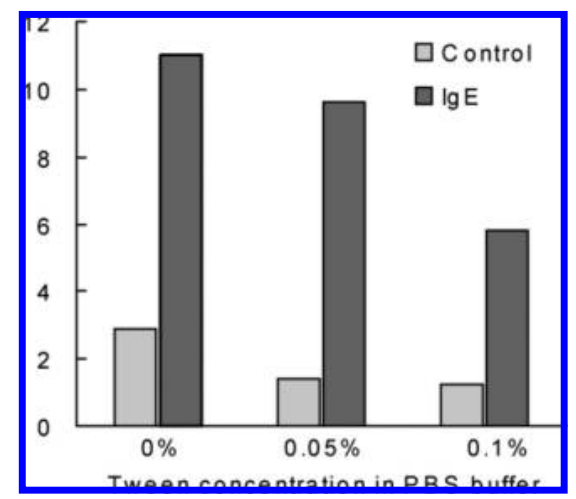

Figure 3. Effect of different binding and washing buffers to minimize the non-specific adsorption. PBS buffers with $0,0.05$, and 0.1 Tween were tested as binding buffer to dilute the MBs, $\lg E$ and $\mathrm{Ab}(\mathrm{D})^{*}$, and as washing buffer used in washing step. Procedures in the couple of experiments were the same as those in Figure 2.

pended in $10 \mu \mathrm{L}$ of coating buffer. A volume of $33.5 \mu \mathrm{L}$ coating buffer, $40 \mu \mathrm{L} \mathrm{Ab}(\mathrm{H})(5 \mathrm{mg} / \mathrm{mL})$ and $41.5 \mu \mathrm{L}$ ammonium sulfate $(3 \mathrm{M})$ were added. The mixture was then incubated for $24 \mathrm{~h}$ at $37^{\circ} \mathrm{C}$ with gentle agitation. The modified MBs were then washed twice with PBST. Finally, the MBs were resuspended in PBST with $0.02 \%$ sodium azide.

Labeling $\mathbf{A b}(\mathrm{D})$ with Alexa Fluor 488. Ten microliters of sodium bicarbonate (1 M, pH 8.3) was added to $100 \mu \mathrm{L}$ of $\mathrm{Ab}(\mathrm{D})$ $(1 \mathrm{mg} / \mathrm{mL})$. The antibody solution was then transferred to fully dissolve the dye while avoiding foaming. The solution was then incubated for $5 \mathrm{~h}$ at room temperature with gentle agitation. Then, the reaction solution was loaded onto a spin column with resin to separate the free dye from the dye-antibody conjugate. After centrifugation at $1100 \mathrm{G}$ for 5 min, the purified labeled antibody was gathered in a collection tube.

The concentration of labeled antibody and degree of labeling were calculated to be $0.46 \mathrm{mg} / \mathrm{mL}$ and 1.84 by the following equations respectively, where 203000 is the molar extinction in $\mathrm{cm}^{-1} \mathrm{M}^{-1}$ of typical $\operatorname{IgG}$ at $280 \mathrm{~nm}$ and 0.11 is a correction factor for the fluorophore's contribution to the absorbance at $280 \mathrm{~nm}$. 
$71000 \mathrm{~cm}^{-1} \mathrm{M}^{-1}$ is the approximate molar extinction coefficient of the Alexa Fluor 488 dye at $494 \mathrm{~nm}$.

Protein concentration $(\mathrm{M})=$

$$
\left[A_{280}-\left(A_{494} \times 0.11\right)\right] \times \text { diluted factor } / 203000
$$

Moles dye per mole protein $=$

$$
A_{494} \times \text { diluted factor/ }(71000 \times \text { protein concentration }(\mathrm{M}))
$$

Procedure for Online Immunocapture and Separation. Step 1: MBs trapping; a uniform suspension of $\mathrm{Ab}(\mathrm{H})$ coated $\mathrm{MBs}$ was injected into the capillary for $10 \mathrm{~min}$ at $34.5 \mathrm{mbar}$. Step 2: Antigen immunocapture; $\mathrm{IgE}$ (reference solutions or diluted sera) was injected for $10 \mathrm{~min}$ at $34.5 \mathrm{mbar}$. Step 3: Labeled antibody immunocapture; $\mathrm{Ab}(\mathrm{D}){ }^{*}$ was injected for $10 \mathrm{~min}$ at $34.5 \mathrm{mbar}$. Step 4: Washing; the washing buffer and LE were injected at 34.5 mbar for 5 and $10 \mathrm{~min}$, respectively, to remove unbound proteins and then totally fill the capillary with the LE. Step 5: Reverse rinsing; a plug of separation buffer was injected at 34.5 mbar from the outlet vial. Step 6: Release and separation of the antigens and labeled antibodies; $15 \mathrm{kV}$ was applied from anode to cathode with electrode compartments filled with separation buffer. As electrophoresis progressed, the $\mathrm{pH}$ in the zone of MBs gradually diminished till a value where the immune complexes were dissociated. The antigens and the labeled antibodies were then released from the MBs, stacked by t-ITP and separated by CZE. Finally, only the labeled antibodies can be detected by LIF. Step 7: MBs removal; the trapped MBs were removed at the end of each analysis by flushing at a high pressure (1379 mbar). The procedure is schematically described in Figure 1. Unfortunately, with the present system, because of the positioning of the magnets, we were not able to image the trapping area with a microscope. We are thus unable to give here a precise evaluation of the dimensions MBs plug.

\section{RESULTS AND DISCUSSION}

Measurement of the Amount of Immobilized $\mathrm{Ab}(\mathrm{H})$ on MBs. After the antibody immobilization procedure, the UV absorption of supernatant was measured and the concentration of unreacted antibody was calculated. The amount of antibody immobilized on the MBs was estimated to be $38 \mu \mathrm{g} / \mathrm{mg}$, via comparing the solution concentration of antibody before and after the coupling reaction.

Labeling of the Secondary Antibody. LIF is one of the most sensitive detection modes in CE, and FITC is the most commonly used labeling dye. However, there is some problem using FITC in the reported IA-CE method because acidic buffers need to be used to dissociate the immune complexes. The fluorescence of FITC is only significant at basic $\mathrm{pH}$ and decreases dramatically under acidic condition. The Alexa Fluor 488 reactive dye (see Supporting Information) is similar to fluorescein in terms of absorption and emission maxima, respectively, around 494 and $519 \mathrm{~nm}$. To know which of the dyes was the most adapted to our system, we used a labeled Anti-IgE to study the fluorescence response as a function of the $\mathrm{pH}$. The corresponding results are available as a Supporting Information file to this article. Even if a significant decrease of fluorescence signal is observed for $\mathrm{pH}$ below 4, the Alexa Fluor conjugate remains fluorescent even under

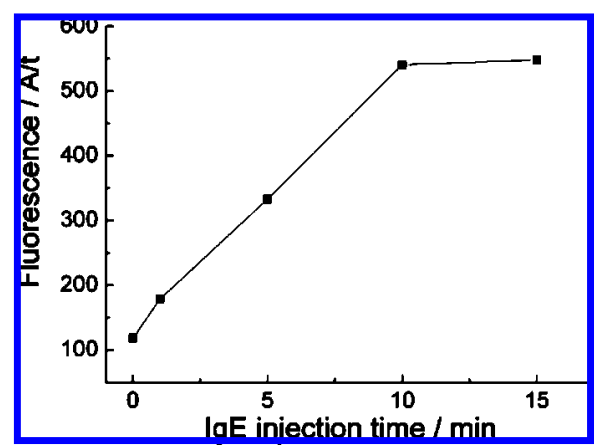

Figure 4. Preconcentration of $\lg E(240 \mathrm{ng} / \mathrm{mL}$ in PBST) by increasing its injection time. Injection (34.5 mbar): MBs for $10 \mathrm{~min}$, IgE for 1 to $15 \mathrm{~min}, A b(D)^{*}$ for $10 \mathrm{~min}$. Other experimental conditions and IACE steps were the same as those in Figure 2.

rather strong acidic condition and was thus chosen as the labeling agent in the presented study.

Minimizing the Non-Specific Adsorption. The described method uses two types of antihuman $\operatorname{IgE}$ antibodies, $\mathrm{Ab}(\mathrm{D})$ and $\mathrm{Ab}(\mathrm{H})$, which react with two different domains, $\mathrm{Ce} 2$ and $\mathrm{Ce} 3$, of the same IgE molecule. ${ }^{33}$ As MBs have been functionalized with $\mathrm{Ab}(\mathrm{H})$, the sandwich immunoassay involves the first reaction between $\mathrm{IgE}$ and immobilized $\mathrm{Ab}(\mathrm{H})$ at the $\mathrm{Ce} 3$ domain. The second reaction then occurs between the $\mathrm{Ce} 2$ domain of $\mathrm{IgE}$ and the secondary labeled antibody, $\mathrm{Ab}(\mathrm{D})^{*}$. To confirm that the eluted $\mathrm{Ab}(\mathrm{D})^{*}$ mainly originates from its specific reaction with the human $\operatorname{IgE}$, previously immobilized on the MBs through its interaction with $\mathrm{Ab}(\mathrm{H})$, and not from its non-specific adsorption on MBs or on capillary walls, the following experiments were performed. To serve as a reference, the successive injections of $\mathrm{MBs}, \mathrm{IgE}$ reference solution, $\mathrm{Ab}(\mathrm{D})^{*}$, washing buffer, and then LE were first performed. Afterward, a given portion of the capillary was filled with the separation buffer before applying an electric field leading successively to the elution, preconcentration, and migration of $\mathrm{Ab}(\mathrm{D})$ * till the detector (Figure $2 \mathrm{~A}$ ). In a second experiment, exactly the same injection sequence was performed except that binding buffer was injected instead of the IgE reference solution (Figure 2B).

While IgEs are prone to react with the surface of the functionalized MBs mainly through specific interactions, labeled antihuman $\mathrm{IgE}$ antibodies, other immunoglobulins and proteins contained in the serum samples could potentially bind to the MBs and capillary walls through non-specific adsorption. As is the case in any type of immunoassays, those kinds of non-specific adsorption should be limited as much as possible to provide a high sensitivity and confidence to the developed technique. Indeed, while the non-specific adsorption of serum constituents to the MBs can hinder the specific interaction of human $\operatorname{IgE}$ with functionalized MBs, the non-specific binding of labeled antihuman $\mathrm{IgE}$ antibody to any part of the system can induce false positive or exaggerate results. Consequently blocking reagents need to be employed. However, in this allergy related $\operatorname{IgE}$ determination, mostly used blocking reagents such as BSA or milk powder can not be used because of their potential allergenic content, which may interfere with the analysis. Fortunately, with the aid of Tween20 , which was added into the binding and washing buffers, nonspecific adsorption can be decreased to an acceptable level. Three kinds of PBS buffers with different concentrations of Tween-20 $(0,0.05$, and $0.1 \%)$ were studied to demonstrate the effect and 


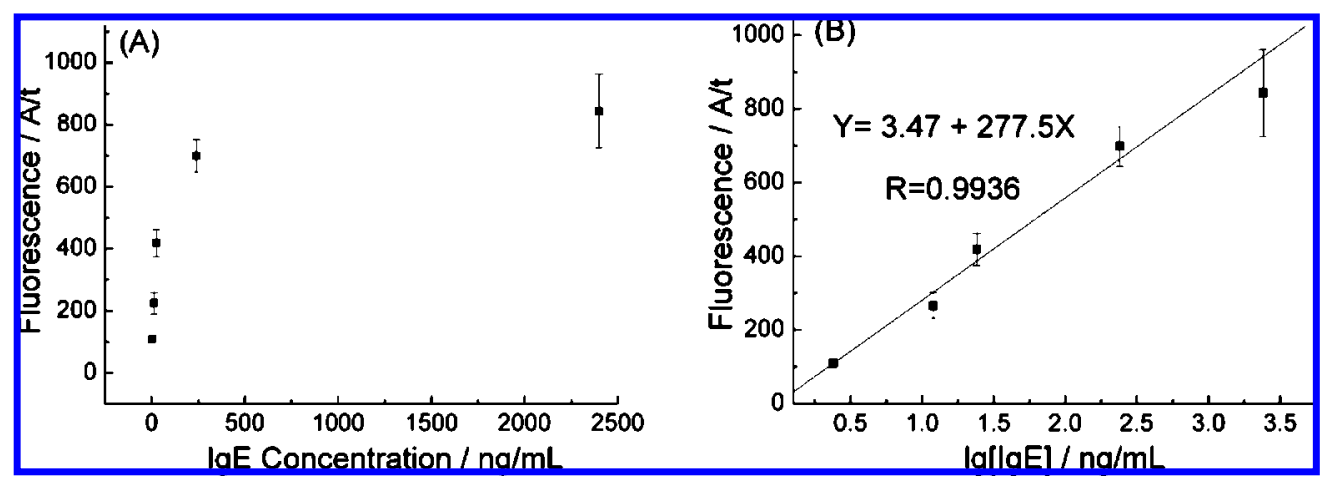

Figure 5. Fluorescence responses of different concentrations of IgE by IA-CE. (A) Fluorescence responses vs concentration of [IgE]; (B) Calibration curves of fluorescence responses vs Ig[lgE]. Injection (34.5 mbar): MBs for $10 \mathrm{~min}$, IgE for $10 \mathrm{~min}, \mathrm{Ab}(\mathrm{D})^{*}$ for $10 \mathrm{~min}$. Other experimental conditions and IA-CE steps were the same as those in Figure 2.

Table 1. Comparison of IgE Determination on Patient Sera by IA-CE and ImmunoCap Methods

\begin{tabular}{|c|c|c|c|c|c|}
\hline \multirow[b]{2}{*}{ serum sample } & \multicolumn{2}{|c|}{ IA-CE/LIF } & \multicolumn{2}{|c|}{ ImmunoCap } & \multirow[b]{2}{*}{$\mathrm{CV}(\%)$} \\
\hline & $\mathrm{ng} / \mathrm{mL}$ & $\mathrm{kIU} / \mathrm{L}$ & $\mathrm{ng} / \mathrm{mL}$ & $\mathrm{kIU} / \mathrm{L}$ & \\
\hline$N A C 3$ & 1994.9 & 831.2 & 2610.6 & 1084 & 18.9 \\
\hline CER 5 & 168.9 & 70 & 216 & 90 & 17.3 \\
\hline
\end{tabular}

find the optimal condition for the use of Tween-20. For each Tween concentration, the same couple of experiments were performed as those in Figure 2. The ratio of specific and non-specific binding was used as a criterion. As shown in Figure 3, both specific and non-specific binding decreased when Tween-20 concentration changed from 0 to $0.05 \%$, while the ratio evolved from 3.8 to 6.8 . However, if the concentration of Tween-20 was further increased to $0.1 \%$, the non-specific binding was kept constant while the specific one decreased significantly inducing a decrease of the ratio between specific and non-specific interaction to 4.7. Such results can be understood considering that too high concentrations of Tween may hinder the immune reaction. Tween concentration of $0.05 \%$ in PBS buffer was thus found to be the best condition for the following experiments. The signal of non-specifically adsorbed $\mathrm{Ab}(\mathrm{D})^{*}$ in control experiment is relatively low as compared to the one relative to specific immune reactions.

Online IA-CE. $\mathrm{Ab}(\mathrm{H})$ coated MBs injection was optimized to obtain maximum loading efficiency and best sensitivity. The MBs were injected for different periods, followed by extended loading of $\operatorname{IgE}$ and $\mathrm{Ab}(\mathrm{D})^{*}$ to make the MBs quantity the limiting factor. Then, after the washing steps that permit to remove the nonspecifically bound antibodies from the capillary, the partial-filling of the capillary with LE and separation buffer was performed as described above. The immune complexes were broken and the involved partners electrophoretically transported toward the detector. $\mathrm{Ab}(\mathrm{D})^{*}$ can then be detected by LIF. The quantity of bound $\mathrm{Ab}(\mathrm{D})$ * increased linearly $\left(\mathrm{R}^{2}=0.985\right)$ with the MBs injection time (till $10 \mathrm{~min}$ ). As the MBs tend to sediment after a while, which may induce a bad reproducibility, no longer than 10 min injection time was tested. Also, much attention had to be paid on the current stability as too large amount of trapped MBs may result in some blocking of the capillary and/or generate bubbles and consequently current instability. A $10 \mathrm{~min}$ injection time, which provides at the same time a stable current and a suitable sensitivity was chosen for the following experiments. Unfortunately, with the developed setup, it was not feasible to image the capillary zone in which the MBs were trapped. Given the chosen configuration of the magnets, the considered zone was hidden and no optical technique could be used for the characterization of the plug of MBs.

The injection time of the secondary labeled antibody, $\mathrm{Ab}(\mathrm{D})$ *, was then optimized. It had to be high enough for allowing the injection of enough molecules to probe all immunocaptured human IgE molecules while not being excessive to keep the nonspecific interaction at a low level. After having loaded $\mathrm{Ab}(\mathrm{H})$ coated MBs for $10 \mathrm{~min}$, and $\mathrm{IgE}(2400 \mathrm{ng} / \mathrm{mL}$ ) for $5 \mathrm{~min}, \mathrm{Ab}(\mathrm{D})$ * $(575 \mathrm{ng} / \mathrm{mL}$ ) was injected from 1 to $10 \mathrm{~min}$. A clear increase of the fluorescence signal till $5 \mathrm{~min}$ with a trend to saturation around $10 \mathrm{~min}$ has been observed. This injection time of $10 \mathrm{~min}$ has thus been chosen for further experiments.

Another feature of the developed IA-CE method, in addition to allow an online immunoselection, is its ability to preconcentrate the target antigen. When the sample presents a low concentration, the injection time can be varied to provide a suitable sensitivity for analysis and/or quantification. With the optimized MBs and $\mathrm{Ab}(\mathrm{D})$ * injection time (10 min for each), a rather low concentration of $\operatorname{IgE}(240 \mathrm{ng} / \mathrm{mL})$ was injected for different periods to show the enrichment effect of the method. As shown in Figure 4, the sensitivity can be linearly improved by increasing the sample injection time from 1 to $10 \mathrm{~min}$, and the binding amount reached a saturation level after 10 min injection. Thus, depending on the sample to be studied, as different sensitivity levels could be achieved, the experimental conditions can be tuned to fulfill the requirements.

Application of the IA-CE Method to Patient Serum Samples. Quantification was made by plotting a calibration curve using known concentrations of human $\mathrm{IgE}$, contained in a commercially available reference material. A highly linear calibration curve, for IgE concentrations ranging from 2.4 to $2400 \mathrm{ng} /$ $\mathrm{mL}$, was obtained between the corrected area of the fluorescence response and the logarithm of the concentration of IgE (Figure $5)$. An average RSD of $10.4 \%(n=3)$ has been obtained in that context.

The feasibility of the IA-CE method for clinical applications was then investigated by analyzing two allergic patient sera, NAC 3 and CER 5. The obtained results were compared with those obtained by classical ImmunoCap testing. Before being analyzed, NAC 3 serum was 40 times diluted in PBST while the CER 5 serum was only diluted 10 times. Three repetitions have been 
performed and RSD $(n=3)$ of 7.2 and $5.5 \%$ have been obtained for NAC 3 and CER 5, respectively. Table 1 summarizes the correlation between the results obtained by IA-CE and ImmunoCap methods.

\section{CONCLUSIONS}

A new CE immunoassay using MBs and LIF detection has been developed and applied to the quantification of total $\operatorname{IgE}$ in human serum. Antihuman $\operatorname{IgE}$ antibody $(\mathrm{Ab}(\mathrm{H}))$ coated MBs $(1.08$ $\mu \mathrm{m})$ have been trapped in a neutrally coated capillary for conducting a sandwich immunoassay of human IgE. A secondary labeled antihuman $\operatorname{IgE}$ antibody $\left(\mathrm{Ab}(\mathrm{D})^{*}\right)$, complementary of $\mathrm{Ab}(\mathrm{H})$ was used as a tracer for LIF detection. The reactivity of both antihuman IgE antibodies was fully preserved in spite of the immobilization and labeling reaction. The miniaturized format of the experimental setup provided a high density of binding sites and rapid mass transfers that allowed all the immunoassay process to happen online without the need of any additional incubation time. After immunocapture at physiological $\mathrm{pH}$ and different washing steps, the partial-filling of the capillary with different buffers and the subsequent application of a voltage led successively to the dissociation of the immune complexes, the t-ITP stacking of $\mathrm{Ab}(\mathrm{D})^{*}$ and its final migration toward the detection point. The developed method was applied to the quantification of $\mathrm{IgE}$ in both reference solutions and two allergic patient sera. Good reproducibility $(\mathrm{RSD}=5.53$ and $7.2 \%(n=3)$ ) was observed and both results were in accordance with those obtained with classical ImmunoCap.
A limit of detection for $\mathrm{IgE}$ of $2.4 \mathrm{ng} / \mathrm{mL}(12.6 \mathrm{pM})$, which is appropriate for allergy diagnosis and comparable to current methods, has been achieved in this work. The developed IA-CE technique is thus sensitive and rapid, while only requiring $1 \mu \mathrm{L}$ of serum to be performed. By functionalizing the MBs with known allergens in the future, the proposed methodology would represent a very valuable immunodiagnosis of allergy as it would not only be possible to determine the total $\operatorname{IgE}$ concentration but also the levels of different specific IgE subpopulations with a single drop of serum. The serum sample volume required is a crucial parameter when young children have to be tested or when a great number of different allergens have to be determined.

\section{ACKNOWLEDGMENT}

Supported by a grant from the European Community (contract no. 12793) project "Allergy Card". H.C. is grateful to the NSFC and MOST for research grants (NSFC No. 90713013, MOST NSSP 2006BAF07B03) and to the EPFL for a visiting postgraduate fellowship.

\section{SUPPORTING INFORMATION AVAILABLE}

Additional information about labeling of the secondary antibody. This material is available free of charge via the Internet at http://pubs.acs.org.

Received for review September 3, 2008. Accepted October 16, 2008.

AC801859E 